\title{
The Effect of Stress Management Model in Quality of Life in Breast Cancer Women
}

\author{
Anahita Khodabakhshi Koolaee, ${ }^{1, *}$ Mohammad Reza Falsafinejad, ${ }^{2}$ and Mohammd Esmaeil \\ Akbari $^{3}$ \\ ${ }^{1}$ Department of Counseling Psychology, Institute of Higher Education of khatam, Khatam University, Tehran, IR Iran \\ ${ }_{3}^{2}$ Department of Measurement and Assessment, Allameh Tabataba'i University, Tehran, IR Iran \\ ${ }^{3}$ Cancer Research Center, Shahid Beheshti University of Medical Sciences, Tehran - Iran \\ *Corresponding author: Anahita Khodabakhshi Koolaee, Department of Counseling Psychology, Khatam University, Tehran, IR Iran. E-mail: anna_khodabakhshi@yahoo.com
}

Received: July 6, 2015; Accepted: July 11, 2015

\begin{abstract}
Background: Breast cancer associates with severs severe distress and stress. Since Because of that, the stress management program can train necessary skills to cope with stress; therefore, the current study investigates the effectiveness of stress management on enhancement of quality of life.

Objectives: The aim of the current study is to examine the effectiveness of stress management model in quality of life for breast cancer patients.

Patients and Methods: This research is a quasi-experimental study with pre and post-tests. The 21 subjects were selected from cancer institute of Imam Khomeini in Tehran in 2014. The participants were allocated to two matched groups based on their pre-test scores. They were assigned randomly to the control and experimental groups. Stress management was conducted with the experimental group during 10 sessions. Then the questionnaire was administered at post-test. Statistical analysis was conducted by using the independent $\mathrm{t}$-test and analysis of variance. The research instrument was the core quality of life questionnaire QLQ-C30.

Results: The results of the independent t-test showed that there is a significant difference between the pretest and post-test scores in the experimental group $(\mathrm{P}<0.05)$. Also, there is no significant difference between means of quality of life subscales and socio demographic of the patients such as; age, education and disease stage $(\mathrm{P}<0.05)$.

Conclusions: The results indicate that stress management can change the irrational and distortion thoughts. So, it enhances the quality of life in breast cancer patients.

Keywords: Quality of Life; Stress Management; Stress; Breast Cancer
\end{abstract}

\section{Background}

Breast cancer is the most common cancer in women (1). Moreover, the incident of breast cancer has increased in Iran (2). Women with breast cancer have psychological distress during diagnosis and treatment (3, 4). Psychological symptoms in breast cancer patients are depression, anxiety, and anger (5). The previous studies showed that depression and anxiety in breast cancer patients led to severe symptoms, longtime of recovery, and poor outcome (6). Many studies indicated that negative effects of chemotherapy and psychological symptoms influence function and quality of life of breast cancer patients $(7,8)$. In other words, fear of disease progression (9), fear of being separated from family (10), fear of complication (11), impairment of body image (12), decreased sexual desire (13) and fear of re- currence (14) cause distress in breast cancer patients. These stress sources contribute to low self-esteem (15), feeling of disappointment and helplessness (16). Therefore, quality of life plays an important role in improving treatment and could even be considered as a medical factor in cancer prognosis. Furthermore, in recent years, quality of life is considered as a major factor in the life of cancer patients. Quality of life is a multidimensional concept that was defined according to the individual's perception of mental, physical, emotional, and social functioning (17). According to the prior studies quality of life in breast cancer patients is less than the normal group $(18,19)$. As a result, the intervention for breast cancer must target psychological and physical issues. Therefore, the intervention which could offer 
the patients coping strategies and reframing positive beliefs may reduce the psychological pressures. Prior studies indicated that psychological interventions such as; cognitive behavioral therapy (20), modification of dysfunctional thoughts (21), problem-solving therapy (22) hypnosis (23) and stress management (24) have effective roles to reduce the psychological symptoms. Diverse behavioral and cognitive techniques (such as; coping strategies, record of thought, cognitive assessment, teaching assertiveness), also, systematic approaches and psychological techniques are used in the stress management such as; imagination, relaxation, meditation and autogenic training. Accordingly, this intervention provides training to increase awareness of sources and indicators of stress, training to notice and replace negative thoughts, and training in cognitive and interpersonal coping skills to improve the ways patients manage stressors and maintain their social support networks (25). Also, the previous findings reveal that optimism (26), coping strategies (27) (such as; acceptance) decrease distress in breast cancer patients. Accordingly as noted above, the aim of the current study is to examine the effectiveness of stress management model in quality of life for breast cancer patients.

\section{Objectives}

The aim of the current study is to examine the effectiveness of stress management model in quality of life for breast cancer patients.

\section{Patients and Methods}

\subsection{Methodology}

This study was conducted in 2014 in Tehran, Iran. The present study is a quasi-experimental research with pre-post test and treatment group. The sample group was composed of 24 breast cancer patients who were interested in the training program from cancer institute, Imam Khomeini Medical Center. This sample was assigned to the treatment and control group with random assignment. The sample size was selected by two main reasons: first previous researches carried out of this section had the same sample size, second the present research was quasi-experimental. In all these research methods, the sample size was fifteen participants in each group. After this selection, 3 patients of control group and 2 patients from treatment group relinquished this study.

Stress management was implanted in 10 sessions (two hours for each session) for the treatment group. So the appropriate techniques of stress management designed to help patients to cope with their stress of disease problem. The material of therapeutic intervention are mentioned below: understanding the concept of stress management (2 sessions), automatic thoughts and Cognitive distortions (2 sessions), rational thoughts replacement (1 session), adaptability and social support ( 1 session), anger management (1 session), increasing self-esteem to adapt with their current situation (1 session) and training self-assertiveness (2 sessions).

The inclusion criteria were as follows: Patients are not in hard condition of disease process, Patients must have a high school diploma as the minimum level of education, Patients must be without any severe mental and physical illnesses, All patients received surgery on their breasts as the main treatment, They did not use narcotic drug, All of the patients did not participate in psychological classes or treatment at the same time.

\subsection{Measurement}

The core quality of life questionnaire (QLQ-C30) is a questionnaire developed to assess the quality of life of cancer patients. It comprised 30 items that measure physical health, emotional, cognitive and social functioning, also 9 subscales; fatigue, pain, nausea, diarrhea, constipation, sleep, appetite and a total dimension's quality of life (28). The consistency reliabilities internal (Cronbach's alpha $>0.70$ ) were reported in Persian version. Then collected data was analyzed by SPSS-20 software. Data was analyzed by utilizing independent and dependent t-test.

\section{Results}

In Table 1, the results of socio-demographic characteristics of all of the participants were indicated. As shown in Table 1, the higher category of age belonged to 41 - 50 (\%57.8) and high level of education was for less than diploma (\%47.3). In addition, 42.1 percent of illness stage of participants was local and loco-regional. As shown in Tables $2-4$, there is no significant difference between means of quality of life's subscales and the other variables such as age, education and illness stage. As shown in Table 5, there is a significant difference between two groups in quality of life and its subscales in the pasttest. Table 6 provides the means, standard deviations, and t-test scores of all the variables. These results demonstrate that stress management has major influence on the quality of life in breast cancer patients. Therefore, the 3 subscales of quality of life changes significantly; physical health: $\mathrm{t}=-5.89, \mathrm{df}=17 . \mathrm{P}=0.002$; functional health: $\mathrm{t}=6.87, \mathrm{df}=17, \mathrm{P}=0.000$; total: $\mathrm{t}=$ 3.94, $\mathrm{df}=17, \mathrm{P}=0.009$. The results in Table 3 showed the significant difference of quality of life between pretest and past test in treatment group; physically health: $t=$ 11.57, $\mathrm{df}=9 . \mathrm{P}=0.00$; functional health: $\mathrm{t}=-8.85, \mathrm{df}=9$, $\mathrm{P}=0.00$; total: $\mathrm{t}=7.44, \mathrm{df}=9, \mathrm{P}=0.000$. Therefore, there is a significant difference between the subscales after intervention $(\mathrm{P}<0.05)$. 
Table 1. Socio-Demographic Characteristic of All Participants in Percent

\begin{tabular}{|c|c|c|}
\hline Variables & $\mathbf{n}_{\mathrm{i}}$ & $\mathbf{C f}^{\mathrm{a}}$ \\
\hline \multicolumn{3}{|l|}{ Age Group, y } \\
\hline $30-40$ & 7 & 36.8 \\
\hline $41-50$ & 11 & 57.8 \\
\hline Higher than 50 & 3 & 5.2 \\
\hline \multicolumn{3}{|l|}{ Education } \\
\hline Less than diploma & 9 & 47.3 \\
\hline Diploma & 8 & 42.1 \\
\hline Higher than diploma & 2 & 10.5 \\
\hline \multicolumn{3}{|l|}{ Disease stage } \\
\hline Local & 8 & 42.1 \\
\hline Loco-regional & 8 & 42.1 \\
\hline Expanded & 3 & 15.7 \\
\hline
\end{tabular}

Table 2. The Comparison of the Functional Dimension of Quality of Life in Patients' Age, Education and Disease Stage

\begin{tabular}{|c|c|c|c|c|c|}
\hline Variable/Source Effect & Total Square & df & Mean Square & $\mathbf{F}$ & Significance Level \\
\hline Age & & & & 0.61 & 0.552 \\
\hline Between group & 243.17 & 2 & 121.58 & & \\
\hline Within group & 3153.70 & 16 & 197.10 & & \\
\hline Total & 3396.87 & 18 & - & & \\
\hline Education & & & & 0.003 & 0.991 \\
\hline Between group & 371.1 & 2 & 88.99 & & \\
\hline Within group & 3395.50 & 16 & 212.21 & & \\
\hline Total & 3396.87 & 18 & - & & \\
\hline Disease stage & & & & 0.64 & 0.553 \\
\hline Between group & 253.39 & 2 & 123.96 & & \\
\hline Within group & 3143.48 & 16 & 196.46 & & \\
\hline Total & 3396.87 & 18 & - & & \\
\hline
\end{tabular}

Table 3. The Comparison of the Total Dimension of Quality of Life in Patients' Age, Education and Disease Stage

\begin{tabular}{|c|c|c|c|c|c|}
\hline Variable/Source Effect & Total Square & df & Mean Square & $\mathbf{F}$ & Significance Level \\
\hline Education & & & & 0.37 & 0.692 \\
\hline Between group & 197.53 & 2 & 98.76 & & \\
\hline Within group & 423.90 & 16 & 264.43 & & \\
\hline Total & 4428.44 & 18 & - & & \\
\hline Age & & & & 1.38 & 0.241 \\
\hline Between group & 651.68 & 2 & 325.84 & & \\
\hline Within group & 3776.76 & 16 & 236.04 & & \\
\hline Total & 4428.44 & 18 & - & & \\
\hline Disease stage & & & & 1.42 & 0.258 \\
\hline Between group & 667.55 & 2 & 333.77 & & \\
\hline Within group & 3760.89 & 16 & 235.05 & & \\
\hline Total & 4428.44 & 18 & - & & \\
\hline
\end{tabular}


Khodabakhshi Koolaee A et al.

\begin{tabular}{|c|c|c|c|c|c|}
\hline $\begin{array}{l}\text { Variable/Source } \\
\text { Effect }\end{array}$ & Total Square & df & Mean Square & $\mathbf{F}$ & Significance Level \\
\hline Education & & & & 0.26 & 0.971 \\
\hline Between group & 121.60 & 2 & 60.80 & & \\
\hline Within group & 1096.56 & 16 & 68.53 & & \\
\hline Total & 1100.10 & 18 & - & & \\
\hline Age & & & & 0.25 & 0.775 \\
\hline Between group & 48.34 & 2 & 17.24 & & \\
\hline Within group & 1065.61 & 16 & 66.60 & & \\
\hline Total & 1100.10 & 18 & - & & \\
\hline Disease stage & & & & 0.54 & 0.599 \\
\hline Between group & 69.97 & 2 & 34.97 & & \\
\hline Within group & 1030.12 & 16 & 64.37 & & \\
\hline Total & 1100.10 & 18 & - & & \\
\hline
\end{tabular}

\begin{tabular}{|c|c|c|c|}
\hline variable & Values $^{a}$ & $T^{b}$ & P Value \\
\hline Physical health & & -5.89 & 0.002 \\
\hline Group 1 & $31.39 \pm 4.35$ & & \\
\hline Group 2 & $43.05 \pm 5.98$ & & \\
\hline Functional & & 6.87 & 0.000 \\
\hline Group 1 & $63.1 \pm 5.13$ & & \\
\hline Group 2 & $41.10 \pm 10.51$ & & \\
\hline Total & & 3.94 & 0.009 \\
\hline Group 1 & $53.86 \pm 9.27$ & & \\
\hline Group 2 & $36.10 \pm 16.13$ & & \\
\hline
\end{tabular}

a Values are presented as mean \pm SD.

b $\mathrm{df}=17$.

\begin{tabular}{|c|c|c|}
\hline Variable/Stage & Values $^{a}$ & $T^{b, c}$ \\
\hline Physical health & & 11.57 \\
\hline Pre & $45.84 \pm 4.87$ & \\
\hline Past & $31.39 \pm 4.35$ & \\
\hline Functional & & -8.85 \\
\hline Pre & $38.17 \pm 8.35$ & \\
\hline Past & $63.01 \pm 5.13$ & \\
\hline Total & & -7.44 \\
\hline Pre & $33.29 \pm 11.16$ & \\
\hline Past & $53.76 \pm 9.27$ & \\
\hline
\end{tabular}

a Values are presented as mean $\pm \mathrm{SD}$.

b $\mathrm{df}=17$.

$c^{c}$ V Value $=0$ 


\section{Discussion}

The current study investigated the effectiveness of stress management in quality of life among the breast cancer patients. This finding is consistent with previous studies conducted in this field (29-32). In other words, the breast cancer patients who received the stress management training have a higher quality of life in comparison with the control group. Irrational and negative automatic beliefs, cognition and thoughts impact the perceptions of patients from breast cancer and their expectation of treatment (33). Therefore, this procedure leads to increasing hopelessness and it causes anxiety and depression in patients (34). Then, it can influence the interpersonal relationships and it contribute to losing family support and social network (35). On the other hand, the principal coping strategies are avoidance and approach. The procedure of avoidance strategy includes ignoring stressor and denial. Avoidant behavior associated with increased anxiety and stress in patients (31). Previous finding showed quality of life in breast cancer patients predicted by coping avoidance strategy. Similarly, Carver et al. suggested several coping such as; acceptance and humor prospectively predicted the lower distress in breast cancer patients (36). Likewise, Dupont et al. (37) showed that intrusive thoughts increased pain, depressive symptoms, and physical function. Training coping strategy with cognitive distortion and negative automatic thoughts can help the patients to replace them with rational thoughts. Then this method influence on the interpersonal relationships and social skills. Also, stress management influenced social life and increased self-esteem with training anger management skills and increased assertiveness.

Prior findings revealed that psychosocial and relaxation treatments can improve emotional adjustment and quality of life in breast cancer patients (38). So, quality of life is considered a goal of any psychosocial and cognitive intervention in breast cancer patients. Based on the results of the current and previous studies, patients can control their complications disease through concept of stress management, rational thoughts replacement, adaptability, anger management, and increasing self-esteem. Although one of the possible limitations of the current study is the lack of willingness of patients to cooperate in the study. It suggests that it applied stress management to improve quality of life in patients with Hepatitis, other types of cancer and Multiple sclerosis.

Stress management model is an effective psychological intervention for chronic disorders like Cancer, Multiple sclerosis, heart attack and so on. In these disorders, patients are facing hard situations in their life and need new coping strategies to stand strong and keep the life going. Stress management offers new viewpoints to patients which can be used to reach the quality of life and challenging the problems of sickness.

\section{Acknowledgments}

Thanks to medical staff of Imam Khomeini Medical hospital and all patients who participated in this study.

\section{Authors' Contributions}

Anahita Khodabakhshi Koolaee offered the idea of research and did the intervention sessions and was in charge of writing the research report. Mohammad Reza Falsafinejad was the statistical counselor and analyzed the data of research. Mohammad Esmail Akbari was scientific counselor in cancer and introduced the women patients for research.

\section{Conflict of Interests}

There is no conflict of interests.

\section{Financial Disclosure}

There is no financial disclosure.

\section{References}

1. Darby SC, Ewertz M, McGale P, Bennet AM, Blom-Goldman U, Bronnum D, et al. Risk of ischemic heart disease in women after radiotherapy for breast cancer. N EnglJ Med. 2013;368(11):987-98.

2. Taheri NS, Bakhshandehnosrat S, Tabiei MN, Kashani E, Rajaei S, Besharat S, et al. Epidemiological pattern of breast cancer in Iranian women: is there an ethnic disparity? Asian Pac J Cancer Prev. 2012;13(9):4517-20.

3. Dedert E, Lush E, Chagpar A, Dhabhar FS, Segerstrom SC, Spiege $\mathrm{D}$, et al. Stress, coping, and circadian disruption among women awaiting breast cancer surgery. Ann Behav Med. 2012;44(1):10-20.

4. Donovan-Kicken E, Caughlin JP. Breast cancer patients' topic avoidance and psychological distress: the mediating role of coping.J Health Psychol. 2011;16(4):596-606.

5. Hoffman CJ, Ersser SJ, Hopkinson JB, Nicholls PG, Harrington JE, Thomas PW. Effectiveness of mindfulness-based stress reduction in mood, breast- and endocrine-related quality of life, and wellbeing in stage 0 to III breast cancer: a randomized, controlled trial.J Clin Oncol. 2012;30(12):1335-42.

6. Hirschfeld RM. The Comorbidity of Major Depression and Anxiety Disorders: Recognition and Management in Primary Care. Prim Care Companion J Clin Psychiatry. 2001;3(6):244-54.

7. Smith EM, Pang H, Cirrincione C, Fleishman S, Paskett ED, Ahles T, et al. Effect of duloxetine on pain, function, and quality of life among patients with chemotherapy-induced painful peripheral neuropathy: a randomized clinical trial. JAMA. 2013;309(13):1359-67.

8. Fagundes CP, Lindgren ME, Shapiro CL, Kiecolt-Glaser JK. Child maltreatment and breast cancer survivors: social support makes a difference for quality of life, fatigue and cancer stress. Eur J Cancer. 2012;48(5):728-36

9. Melchior H, Buscher C, Thorenz A, Grochocka A, Koch U, Watzke B. Self-efficacy and fear of cancer progression during the year following diagnosis of breast cancer. Psychooncology. 2013;22(1):39-45.

10. Drageset S, Lindstrom TC, Giske T, Underlid K. Being in suspense: women's experiences awaiting breast cancer surgery. J Adv Nurs. 2011;67(9):1941-51.

11. Garcia-Ortega MJ, Benito MA, Vahamonde EF, Torres PR, Velasco $\mathrm{AB}$, Paredes MM. Pretreatment axillary ultrasonography and core biopsy in patients with suspected breast cancer: diagnostic accuracy and impact on management. Eur J Radiol. 2011;79(1):64-72.

12. Falk Dahl CA, Reinertsen KV, Nesvold IL, Fossa SD, Dahl AA. A study of body image in long-term breast cancer survivors. Cancer. 2010;116(15):3549-57.

13. Ussher JM, Perz J, Gilbert E. Changes to sexual well-being and intimacy after breast cancer. Cancer Nurs. 2012;35(6):456-65. 
14. Koch L, Jansen L, Brenner H, Arndt V. Fear of recurrence and disease progression in long-term $(>\mid=5$ years) cancer survivors-a systematic review of quantitative studies. Psychooncology. 2013;22(1):1-11.

15. Wong-Kim EC, Bloom JR. Depression experienced by young women newly diagnosed with breast cancer. Psychooncology. 2005;14(7):564-73.

16. Levine EG, Yoo G, Aviv C, Ewing C, Au A. Ethnicity and spirituality in breast cancer survivors. J Cancer Surviv. 2007;1(3):212-25.

17. Wong CK, Lo YY, Wong WH, Fung CS. The associations of body mass index with physical and mental aspects of health-related quality of life in Chinese patients with type 2 diabetes mellitus: results from a cross-sectional survey. Health Qual Life Outcomes. 2013;11:142.

18. Engel J, Schlesinger-Raab A, Emeny R, Holzel D, Schubert-Fritschle G. Quality of life in women with localised breast cancer or malignant melanoma 2 years after initial treatment: a comparison. Int J Behav Med. 2014;21(3):478-86.

19. Deshpande AD, Sefko JA, Jeffe DB, Schootman M. The association between chronic disease burden and quality of life among breast cancer survivors in Missouri. Breast Cancer Res Treat. 2011;129(3):877-86.

20. Duijts SF, van Beurden M, Oldenburg HS, Hunter MS, Kieffer JM, Stuiver MM, et al. Efficacy of cognitive behavioral therapy and physical exercise in alleviating treatment-induced menopausal symptoms in patients with breast cancer: results of a randomized, controlled, multicenter trial. J Clin Oncol. 2012;30(33):4124-33.

21. Khan RS, Ahmed K, Blakeway E, Skapinakis P, Nihoyannopoulos L, Macleod K, et al. Catastrophizing: a predictive factor for postoperative pain. Am J Surg. 2011;201(1):122-31.

22. Tsuchiya M, Horn S, Ingham R. Information provision and problem-solving processes in Japanese breast cancer survivors with lymphoedema symptoms. Scand J Caring Sci. 2012;26(1):53-60.

23. Jensen MP, Gralow JR, Braden A, Gertz KJ, Fann JR, Syrjala KL. Hypnosis for symptom management in women with breast cancer: a pilot study. Int J Clin Exp Hypn. 2012;60(2):135-59.

24. Loprinzi CE, Prasad K, Schroeder DR, Sood A. Stress Management and Resilience Training (SMART) program to decrease stress and enhance resilience among breast cancer survivors: a pilot randomized clinical trial. Clin Breast Cancer. 2011;11(6):364-8.

25. Yanez B, Bustillo NE, Antoni MH, Lechner SC, Dahn J, Kava B, et al. The importance of perceived stress management skills for patients with prostate cancer in active surveillance.J Behav Med. 2015;38(2):214-23.

26. Von Ah D, Kang DH, Carpenter JS. Stress, optimism, and social support: impact on immune responses in breast cancer. Res Nurs
Health. 2007;30(1):72-83.

27. Kershaw T, Northouse L, Kritpracha C, Schafenacker A, Mood D. Coping strategies and quality of life in women with advanced breast cancer and their family caregivers. Psychology \& Health. 2004;19(2):139-55.

28. Montazeri A, Goshtasebi A, Vahdaninia M, Gandek B. The Short Form Health Survey (SF-36): translation and validation study of the Iranian version. Qual Life Res. 2005;14(3):875-82.

29. Penedo FJ, Molton I, Dahn JR, Shen BJ, Kinsinger D, Traeger L, et al A randomized clinical trial of group-based cognitive-behavioral stress management in localized prostate cancer: development of stress management skills improves quality of life and benefit finding. Ann Behav Med. 2006;31(3):261-70.

30. Jacobsen PB, Donovan KA, Vadaparampil ST, Small BJ. Systematic review and meta-analysis of psychological and activitybased interventions for cancer-related fatigue. Health Psychol. 2007;26(6):660-7.

31. Faul LA, Jim HS, Williams C, Loftus L, Jacobsen PB. Relationship of stress management skill to psychological distress and quality of life in adults with cancer. Psychooncology. 2010;19(1):102-9.

32. Antoni MH, Lechner SC, Kazi A, Wimberly SR, Sifre T, Urcuyo KR, et al. How stress management improves quality of life after treatment for breast cancer. J Consult Clin Psychol. 2006;74(6):1143-52.

33. Alcalar N, Ozkan S, Kucucuk S, Aslay I, Ozkan M. Association of coping style, cognitive errors and cancer-related variables with depression in women treated for breast cancer. Jpn J Clin Oncol. 2012;42(10):940-7.

34. Robinson JD, Hoover DR, Venetis MK, Kearney TJ, Street RJ. Consultations between patients with breast cancer and surgeons: a pathway from patient-centered communication to reduced hopelessness. JClin Oncol. 2013;31(3):351-8.

35. Nausheen B, Gidron Y, Peveler R, Moss-Morris R. Social support and cancer progression: a systematic review. J Psychosom Res. 2009;67(5):403-15.

36. Carver CS, Pozo C, Harris SD, Noriega V, Scheier MF, Robinson DS, et al. How coping mediates the effect of optimism on distress: a study of women with early stage breast cancer.J Pers Soc Psychol. 1993;65(2):375-90.

37. Dupont A, Bower JE, Stanton AL, Ganz PA. Cancer-related intrusive thoughts predict behavioral symptoms following breast cancer treatment. Health Psychol. 2014;33(2):155-63.

38. Mehnert A, Koch U. Psychological comorbidity and health-related quality of life and its association with awareness, utilization, and need for psychosocial support in a cancer register-based sample of long-term breast cancer survivors. J Psychosom Res. 2008;64(4):383-91. 